\title{
Safety of Multiple Intrathecal Administrations of Cultured Human Autologous Adipose-Derived Stem Cells in the Patients with Neurological Disorders Including Parkinson's Disease
}

\author{
Jeong-Chan Ra*, Hyo Jung Choi and Yoon Kim
}

Biostar Stem Cell Research Institute, IT Castle, Gasan Digital 2-ro, Geumcheon-gu, Seoul, Korea

\begin{abstract}
Although autologous adipose stem cells have much therapeutic potential for incurable diseases, safety concerns have been constantly raised for clinical use. An intrathecal injection of the stem cells to improve therapeutic efficiency in central nervous system diseases is also reluctant due to concerns of adverse reaction. To investigate the safety of multiple intrathecal administrations of autologous adipose-derived mesenchymal stem cells (hAdMSCs), adverse reactions were analyzed by questionnaire survey and blood chemistry examination in 70 patients with Parkinson's disease and other neurodegenerative diseases who received hAdMSCs multiple times in China and Japan, retrospectively. As results, multiple IT administrations of cultured autologous hAdMSCs were safe, although mild back pain at the injection site in 4 patients and headache, dizziness, fever and asleep legs in other 4 patients. Adverse reactions were disappeared completely without specific treatment within a day. There were no serious adverse reactions during the cell treatment period. No remarkable atypical clinical change was observed in the blood analysis before and after the cell administrations. This study demonstrates that multiple IT administrations of hAdMSCs are safe for clinical use.
\end{abstract}

Keywords: Autologous adipose-derived mesenchymal stem cells; Intrathecal injection; Safety

Abbreviations: AD: Alzheimer's Disease; ALT: Alanine Aminotransaminase; AST: Aminotransferase; BMSCs: Bone Marrow Stem Cells; BUN: Blood Urea Nitrogen; CNS: Central Nervous System; DMEM: Dulbecco's Modified Eagle's Medium; FBS: Fatal Bovine Serum; hAdMSCs: Human Adipose-Derived Mesenchymal Stem Cell; HbA1c: Glycated Hemoglobin; HBsAg: Antigen of the Hepatitis B Virus; HCV: Hepatitis C Virus; HIV: Human Immunodeficiency Virus; IT: Intrathecal; IV: Intravenous; ND: Neurodegenerative Diseases; PBS: Phosphate-Buffered Saline; PD: Parkinson's Disease; VDRL: Venereal Disease Research Laboratory; $\gamma$-GTP: $\gamma$-Glutamyl Transpeptidase

\section{Introduction}

Parkinson's disease (PD) is a neurodegenerative disease (ND) showing the progressive abnormal motor symptoms such as rigidity, tremor, bradykinesia, akinesia and the dopaminergic neuronal loss accompanied by the formation of Lewy body that is primarily composed of aggregated $\alpha$-synuclein in the brain [1]. Long-term loss of dopaminergic neurons in the nigrostriatal dopaminergic pathway leading to dopamine depletion is closely related to the major motor symptoms in the PD patients [2,3].

Several available PD medications to compensate dopamine levels in the brain improve symptoms at early stage of the diseases but do not stop or slow down the progression of the disease [4]. Moreover, longterm treatment of dopaminergic drugs causes undesirable side effects such as dyskinesia and wearing off [4,5]. Although many more studies are required to clear the cause of dyskinesia, therapeutic drug capable of disease modification would make possible to retard or stop severe and irreversible behavioral impairments without these adverse effects at late stage of the disease [6].

Stem cell-based therapy have been expected as a hopeful diseasemodifying approach for the ND including PD and Alzheimer's disease [AD] [7-9]. Because stem cell transplantation can rescue neuronal loss in the brain by substitution of lost cells, cell combination, release of neurotrophic factors, proliferation of endogenous stem cells, and transdifferentiation $[10,11]$.
Preclinical and clinical studies for stem cells have proven to have therapeutic potential for PD. Neural precursor cells from embryonic stem cells, neural stem cells and bone marrow stem cells (BMSCs) provided therapeutic abilities when they were grafted in animal models of PD [12-14].

In recent animal studies, intravenous (IV) transplantation of human adipose-derived mesenchymal stem cell (hAdMSCs) isolated from adipose tissue showed therapeutic effects in 6-hydroxydopa-induced PD mouse by the recovery of dopaminergic neurons and the restoration of cytosolic mitochondria [15]. Both intracerebral and IV injection of hAdMSCs improved motor abilities by returning dopaminergic cell numbers to normal in 1-methyl-4-phenyl-1,2,3,6-tetrahydropyridineinduced PD mouse [16].

Stem cell therapy for the patients is limited because of concerns about safety, in particular carcinogenicity rather than efficacy of stem cells $[17,18]$. However, our previous retrospective research clearly demonstrated that no seriously concerned adverse effects-such as tumorigenicity were observed after multiple IV administrations of cultured hAdMSCs to normal subjects and patients for 3 years [19].

IT injection of therapeutic drugs has tried to improve therapeutic efficiency in CNS diseases despite the inconvenience of the patient [20]. The problem remains to be solved as an administration route for stem cell therapy. Multiple IT administrations of hAdMSCs would induce unexpected side effects due to direct exposure of cultured stem cells into cerebrospinal fluid. Therefore, it is the most important to confirm safety

*Corresponding author: Jeong-Chan Ra, Biostar Stem Cell Research Institute 2-305 IT Castle, 98 Gasan digital 2-ro, Geumcheon-gu, Seoul, Korea, Tel: +822-070-4665-1174; E-mail: jcra@stemcellbio.com

Received October 25, 2018; Accepted October 27, 2018; Published October 29, 2018

Citation: Jeong-Chan Ra, Hyo Jung Choi, Yoon Kim (2018) Safety of Multiple Intrathecal Administrations of Cultured Human Autologous Adipose-Derived Stem Cells in the Patients with Neurological Disorders Including Parkinson's Disease. J Clin Case Rep 8: 1183. doi: 10.4172/2165-7920.10001183

Copyright: @ 2018 Jeong-Chan Ra, et al. This is an open-access article distributed under the terms of the Creative Commons Attribution License, which permits unrestricted use, distribution, and reproduction in any medium, provided the original author and source are credited. 
Citation: Jeong-Chan Ra, Hyo Jung Choi, Yoon Kim (2018) Safety of Multiple Intrathecal Administrations of Cultured Human Autologous AdiposeDerived Stem Cells in the Patients with Neurological Disorders Including Parkinson's Disease. J Clin Case Rep 8: 1183. doi: 10.4172/21657920.10001183

Page 2 of 6

of repeated IT administrations of hAdMSCs before entering main clinical studies.

To identify safety of IT administration further, we analyzed side effects observed in 70 patients who suffered from PD or other ND during repeated stem cell treatments. They received hAdMSCs via IT treatment route from minimum once to maximum 25 times in China and Japan from 2009 to 2017.

\section{Materials and Methods}

\section{The subjects participated in the study}

Seventy patients who have Parkinson's disease, dementia or other neurological disorders were recruited in Japan and China. All subjects were Asian, and their age was widely distributed from 52 to 89 years and the average was $71.53 \pm 7.73$ (Table 1). The study consisted of 38 men and 32 women patients. The subjects were selected according to inclusion and exclusion criteria as below. The case inclusion criteria were as follows:

(1) Age 50 years or older.

(2) Patients who received hAdMSCs minimum one time.

(3) Able to provide informed consent.

(4) Clinical diagnosis of Parkinson disease, dementia or other neurological disorders.

(5) Patients are healthy enough to undergo the research protocol.

(6) Patients living at home or in the community.

(7) Able to read and speak Korean.

The case exclusion criteria were as follows:

(1) Uncontrolled medical condition requiring immediate treatment that would make a walking trial unsafe for the subject.

(2)Current or recent orthopedic disorder that severely limits gait.

(3) Any current acute psychosis, alcohol abuse or drug abuse.

(4)Clinical trial intervention wishing the last 6 months.

(5) Patients living in a continuous care nursing facility.

This study was approved by the institutional review boards at the BIOSTAR Stem Cell Research Institute. Ltd., Seoul, Korea.

\section{Cell preparation from the patients}

Human adipose tissues of the patients were gained from abdominal subcutaneous fats. The tissues were gradually stirred with $1 \mathrm{mg} / \mathrm{ml}$ of collagenase I for $60 \mathrm{~min}$ at $37^{\circ} \mathrm{C}$ for digesting. After $60 \mathrm{~min}$, the tissues were filtered out through a $100 \mathrm{mM}$ nylon sieve to eliminate cellular debris and centrifuged at $470 \mathrm{~g}$ for $5 \mathrm{~min}$ to gain a pallet. The pallet was suspended in Dulbecco's modified Eagle's medium (DMEM; Invitrogen)-based media containing $0.2 \mathrm{mM}$ ascorbic acid and $10 \%$ fatal bovine serum (FBS) which was gained from bovine spongiform encephalopathy free herb and centrifuged again. The Cell pellet was assembled and the supernatant was removed. The part of cell was cultured at $37^{\circ} \mathrm{C} / 5 \%$ CO in DMEM overnight. After $24 \mathrm{~h}$, the cell adhesive strength was inspected by an inverted microscope and removed non-adherent cell by washing with phosphate-buffered saline (PBS). The cell medium was altered as Keratinocyte-SFM (Invitrogen)based media containing $0.2 \mathrm{mM}$ ascorbic acid, $0.09 \mathrm{mM}$ calcium, $5 \mathrm{ng} /$ $\mathrm{ml} \mathrm{rEGF}$ and 5\% FBS. The cells retained around 5 days for confluency. They were subculture-expanded in Keratinocyte-SFM-based media containing $0.2 \mathrm{mM}$ ascorbic acid, $0.09 \mathrm{mM}$ calcium, $5 \mathrm{ng} / \mathrm{ml} \mathrm{rEGF}$ and $5 \%$ FBS when the confluency arrived $90 \%$. The cells were washed with PBS and thereby FBS was completely removed and demonstrated the albumin measurement limit using a bovine albumin ELISA quantitation kit (Bethyl Laboratories). The procedure for the cell preparation was performed under Good manufacturing practices in the Biostar Stem Cell Research Center.

\section{History of hAdMSCs treatment}

The IT injection was conducted in Japan and China according to the guidelines of the Declaration of Helsinki and Tokyo for humans and approved by the institutional review board. $5 \times 10^{7}$ adipose-derived mesenchymal stem cells in $0.3 \mathrm{cc}$ of injectable saline were given in once a month to the patients into the spinal cord over 5 minutes through lumbar spinal tapping. They received the stem cells from minimum once to maximum 25 times in China and Japan from 2009 to 2017.

\section{Measurement}

The normal daily dietary intake was recommended during the study. The patients maintained their daily life without any specific activity. The clinical pathology examination was conducted at the first visit to evaluate the physical health status of the subjects before the first IT injection of the cells and after the last IT injection of the cells and the last visits. Examination items included blood chemistry screen; glucose, total protein, albumin, aspartate aminotransferase (AST), alanine aminotransaminase (ALT), $\gamma$-glutamyl transpeptidase ( $\gamma$-GTP), triglyceride (TG), blood urea nitrogen (BUN), creatinine (CRTN), and total cholesterol. HbAlc, HBsAg, HCV, HIV, and VDRL were tested, too. Clinically significant abnormal changes between the first visit and last visit were recorded as the adverse reactions of the subjects.

\section{Safety assessment}

The investigator determined the severity of each adverse reaction observed during repeated treatments of hAdMSCs and until last visits after final IT administration of the cells. The information about the adverse reactions was identified by non-directive questions to the subjects when the patients visited the hospitals. Furthermore, voluntary reports from the subject were recorded in detail during the test period. They included the date of symptom onset and disappearance, and adverse reaction level.

The safety assessment in the patients was conducted in frequency and severity of adverse reaction and clinical laboratory examination (blood chemistry test).

\section{Results}

\section{The subject enrollment and treatment}

For safety assessment, we analyzed adverse reactions observed in 70 patients who have the central nervous system diseases including Parkinson's disease and other neurological diseases (Table 1). They were 38 men and 32 women. Ages are widely distributed from 50 to 80 years (6 patients in 50s, 18 patients in 60s, 38 patients in 70 s and 8 patients in 80s). All patients were classified according to the time elapsed since the last IT administration of hAdMSC (Figure 1). Twenty-two patients were less than 1 years after the last IT administration of hAdMSC. Seven patients were less than 2 years. Seven patients were less than 3 years and five patients were less than 4 years. Six patients were less than 
Citation: Jeong-Chan Ra, Hyo Jung Choi, Yoon Kim (2018) Safety of Multiple Intrathecal Administrations of Cultured Human Autologous AdiposeDerived Stem Cells in the Patients with Neurological Disorders Including Parkinson's Disease. J Clin Case Rep 8: 1183. doi: 10.4172/21657920.10001183

Page 3 of 6

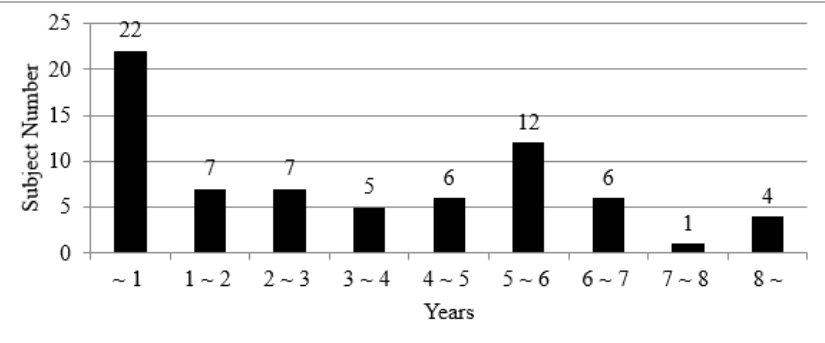

Figure 1: Classification of patients according to the time elapsed since the last IT administration of hAdMSC. $Y$ axis means the number of patients. $X$ axis means years since the last IT administration of hAdMSC. Thirty-six patients were within 3 years after the last IT administration of hAdMSC. Thirtyfour patients were between 4 years and 9 years. Two patients were over eight years.

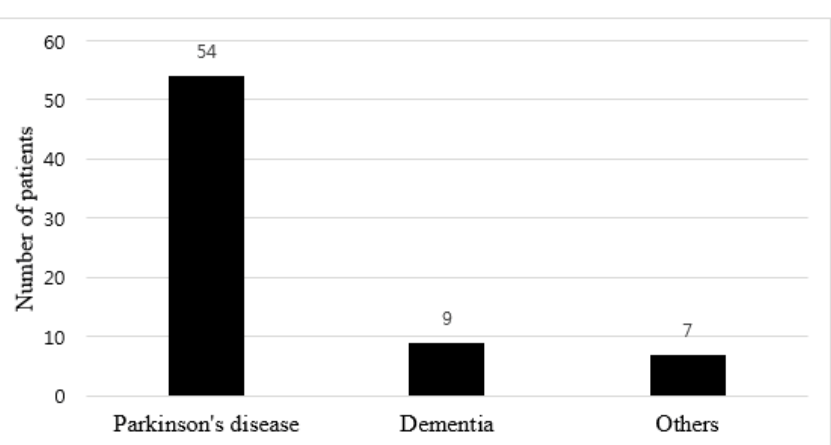

Figure 2: Disease types of the patients who received multiple IT administrations of hAdMSCs. Each patient had an underlying medical condition which is relevant to neurological disorders. Arabic numbers over the black bar mean patient number. $Y$ axis represents patient number. $X$ axis represents disease types of patients.

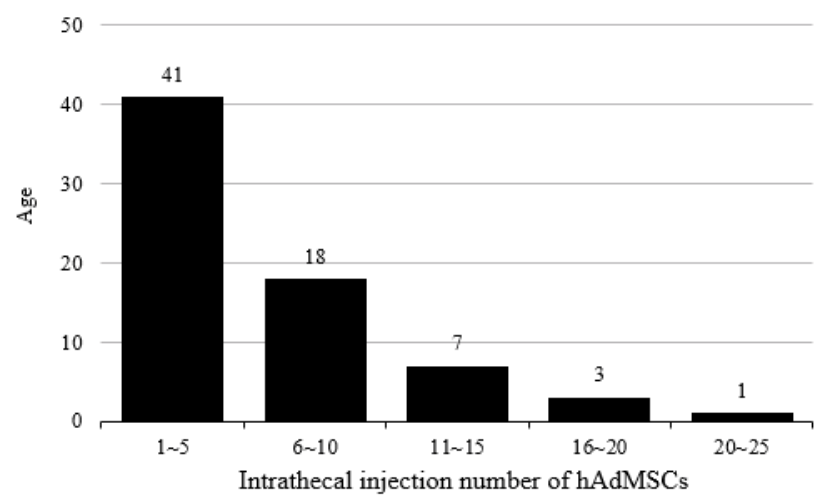

Figure 3: Number of IT administrations of hAdMSCs to the patients. Arabic numbers over the black bar mean patient number. $X$ axis represents IT injection number. $Y$ axis represents age of patients.

5 years and twelve patients were less than 6 years. Six patients were less than 7 years and one patient was less than 8 years. Four patients were more than 8 years.

Thirty-six patients were within 3 years after the last IT administration of hAdMSC. Thirty-four patients were between 4 years and 9 years. Two patients were over eight years. Mean time passed since the last injection of hAdMSC was $37.56 \pm 31.52$ months.

\begin{tabular}{|c|c|c|c|c|c|}
\hline Sex Age (years) & $50 \sim 60$ & $60 \sim 70$ & $70 \sim 80$ & 80 90 & Total \\
\hline Male & 4 & 10 & 21 & 3 & 38 \\
\hline Female & 2 & 8 & 17 & 5 & 32 \\
\hline Total & 6 & 18 & 38 & 8 & 70 \\
\hline
\end{tabular}

Table 1: The number, sex, and age of patients enrolled for the safety assessment.

\begin{tabular}{|c|c|c|c|c|c|c|}
\hline $\begin{array}{c}\text { Number of IT } \\
\text { treatments }\end{array}$ & $\mathbf{1 \sim 5}$ & $\mathbf{6 \sim 1 0}$ & $\mathbf{1 1 \sim 1 5}$ & $\mathbf{1 6 \sim 2 0}$ & $\mathbf{2 1 \sim 2 5}$ & $\begin{array}{c}\text { Total } \\
\text { Patient Number }\end{array}$ \\
\hline None & 37 & 15 & 6 & 3 & 1 & 62 \\
\hline Back pain & 3 & 1 & 0 & 0 & 0 & 4 \\
\hline Headache & 0 & 1 & 0 & 0 & 0 & 1 \\
\hline Dizziness & 0 & 1 & 0 & 0 & 0 & 1 \\
\hline Fever & 0 & 0 & 1 & 0 & 0 & 1 \\
\hline asleep legs & 1 & 0 & 0 & 0 & 0 & 1 \\
\hline Total & 41 & 18 & 7 & 3 & 1 & 70 \\
\hline
\end{tabular}

Five types of adverse reactions observed were counted according to number of IT treatments. None means any adverse reaction was not appeared.

Table 2: Adverse reactions observed in the patients during multiple IT administrations of hAdMSCs.

Fifty-four patients had Parkinson's disease, nine patients had dementia and seven patients had other diseases such as $\mathrm{AD}$, meningitis, depression, cognitive impairment, and brain damage (Figure 2).

Each patient received hAdMSCs multiple times from once to 25 times (once a month) for 9 years (Figure 3). 41 patients received 1 5 times, 18 patients received $6 \sim 10$ times, 7 patients received $11 \sim 15$ times, 3 patients received 16 20 times and 1 patient received 20 25 times. The minimum injection number was once, and the maximum injection number was 25 times. Mean injection numbers for all patients were 6 times.

\section{Safety assessment}

Five types of adverse reactions were observed in the patients after multiple IT administrations of hAdMSCs. Fifty-three patients of 70 patients did not show any side effects related to IT administration. Mild back pain at the injection site were appeared in 4 patients. Headache, dizziness, fever and asleep legs in other 4 patients, respectively were observed during the treatment period. All adverse reactions were resolved completely and spontaneously without specific treatment and were not related to the IT treatment (Table 2).

Blood chemistry analysis results were not compared in all patients. The patients who did not agree on the post-treatment test were excluded in the blood chemistry test after IT treatment. The blood chemistry data for 19 patients who agreed on the post-treatment test were analyzed to identify whether IT treatment of the cells could induce adverse reactions.

In blood chemistry analysis before IT administration of hAdMSC (Table 3), there was no abnormal value in total protein level and albumin level. 2 patients were abnormal values in AST levels, 1 patient was in ALT level, 3 patients were in r-GTP levels, 4 patients were in total cholesterol, 4 patients were in TG levels, 2 patients were in BUN levels, 3 patients were in CRTN levels, 2 patients were in HbAlc levels. Every patient was negative in HBsAg, HCV, HIV and VDRL. Average values for all analysis items were in normal range. Blood chemistry analysis after last IT administration of hAdMSC was carried out to check safety profile in the patients who received hAdMSC. 1 patient was abnormal in total protein level, 1 patient was in albumin level, 2 patients were in AST levels, 2 patients were in ALT levels, 4 patients were in r-GTP levels, 5 patients were in total cholesterol, 6 patients were in TG levels, 5 
Citation: Jeong-Chan Ra, Hyo Jung Choi, Yoon Kim (2018) Safety of Multiple Intrathecal Administrations of Cultured Human Autologous AdiposeDerived Stem Cells in the Patients with Neurological Disorders Including Parkinson's Disease. J Clin Case Rep 8: 1183. doi: 10.4172/21657920.10001183

Page 4 of 6

\begin{tabular}{|c|c|c|c|c|c|c|c|c|c|}
\hline \multirow[b]{2}{*}{ Parameter } & \multirow[b]{2}{*}{$\begin{array}{l}\text { Normal } \\
\text { range } \\
\text { value }\end{array}$} & \multicolumn{4}{|c|}{ Before IT administration of hAdMSC } & \multicolumn{4}{|c|}{ After IT administration of hAdMSC } \\
\hline & & $\begin{array}{c}\text { Patient } \\
\text { number in } \\
\text { normal range }\end{array}$ & $\begin{array}{c}\text { Patient number } \\
\text { in abnormal } \\
\text { range }\end{array}$ & Average \pm SD & $\begin{array}{c}\text { Total patient } \\
\text { number }\end{array}$ & $\begin{array}{c}\text { Patient } \\
\text { number in } \\
\text { normal range }\end{array}$ & $\begin{array}{c}\text { Patient number } \\
\text { in abnormal } \\
\text { range }\end{array}$ & $\begin{array}{l}\text { Average } \\
\pm \mathrm{SD}\end{array}$ & $\begin{array}{c}\text { Total } \\
\text { patient } \\
\text { number }\end{array}$ \\
\hline Total protein & $6.7 \sim 8.3$ & 19 & 0 & $7.53 \pm 0.36$ & 19 & 18 & 1 & $7.40 \pm 0.51$ & 19 \\
\hline Albumin & $3.8 \sim 5.3$ & 19 & 0 & $4.31 \pm 0.22$ & 19 & 18 & 1 & $4.26 \pm 0.25$ & 19 \\
\hline $\begin{array}{l}\text { Aspartate aminotransferase } \\
\text { (AST), }\end{array}$ & $8 \sim 38$ & 17 & 2 & $26.89 \pm 9.31$ & 19 & 17 & 2 & $\begin{array}{c}28.16 \pm \\
10.88\end{array}$ & 19 \\
\hline $\begin{array}{l}\text { Alanine aminotransaminase } \\
(\mathrm{ALT})\end{array}$ & $4 \sim 44$ & 18 & 1 & $23.37 \pm 11.21$ & 19 & 17 & 2 & $\begin{array}{l}27.32 \pm \\
21.43\end{array}$ & 19 \\
\hline $\begin{array}{c}\text { gamma-glutamyl } \\
\text { transpeptidase }(\mathrm{Y}-\mathrm{GTP})\end{array}$ & $16 \sim 73$ & 16 & 3 & $33.42 \pm 20.88$ & 19 & 15 & 4 & $\begin{array}{l}33.79 \pm \\
24.33\end{array}$ & 19 \\
\hline Total cholesterol & $125 \sim 223$ & 15 & 4 & $183.53 \pm 37.94$ & 19 & 14 & 5 & $\begin{array}{c}196.74 \pm \\
43.03\end{array}$ & 19 \\
\hline TG & $45 \sim 150$ & 15 & 4 & $110.16 \pm 52.91$ & 19 & 13 & 6 & $\begin{array}{c}142.21 \pm \\
134.25 \\
\end{array}$ & 19 \\
\hline BUN & $8 \sim 20$ & 17 & 2 & $16.22 \pm 5.10$ & 19 & 14 & 5 & $\begin{array}{c}18.69 \pm \\
4.88\end{array}$ & 19 \\
\hline CRTN & $0.7 \sim 1.3$ & 16 & 3 & $1.01 \pm 0.24$ & 19 & 16 & 3 & $1.04 \pm 0.26$ & 19 \\
\hline $\mathrm{HbA1c}$ & $4.0 \sim 6.0$ & 16 & 3 & $5.90 \pm 0.92$ & 19 & 13 & 6 & $5.93 \pm 1.18$ & 19 \\
\hline $\mathrm{HBs} \mathrm{Ag}$ & Negative & 19 & 0 & - & 19 & 19 & 0 & - & 19 \\
\hline $\mathrm{HCV}$ & Negative & 19 & 0 & - & 19 & 19 & 0 & - & 19 \\
\hline HIV & Negative & 19 & 0 & - & 19 & 19 & 0 & - & 19 \\
\hline VDRL & Negative & 19 & 0 & - & 19 & 19 & 0 & - & 19 \\
\hline
\end{tabular}

Table 3: Blood chemistry parameter values in the patients before and after IT administration of hAdMSCs.

patients were in BUN levels, 3 patients were in CRTN levels, 6 patients were in $\mathrm{HbA1}$ c levels. Every patient was negative in $\mathrm{HBsAg}, \mathrm{HCV}, \mathrm{HIV}$ and VDRL. Average values for all analysis items were in normal range.

\section{Discussion}

Recently, many researchers have investigated the efficacy of MSCs to find new therapeutic way for the incurable, irreversible and fatal diseases including ND [21].

However, clinical use of MSCs has been limited because there have been suggested variable risk factors of stem cell-base therapy. Multiple risk factors resulting from cell characteristics (origin of cells, tumorigenic potential, proliferation capacity), manufacturing and handling (culture procedure, disease transmission, cell line contamination, neoplasm formation, storage and delivery condition), clinical characteristics (administration route, exposure duration, unwanted immune response, unwanted engraftment, toxicity) could contribute to the risks of stem cell therapy in patients [18].

Considering the low viability and retention time of the stem cell, many cells should be administered to obtain better clinical results. However, the concentrated cells may aggregate while passing through the syringe needle into the vein, resulting in side effects such as obstruction of the blood vessels [17]. Vidula et al. [22] demonstrated that a higher dose of stem cell was associated with more side effects in the patients with cancer undergoing stem cell treatments.

Administration route change have been suggested to overcome the risks of stem cell therapy in the clinic. The administration of stem cells at specific locations, such as the administration to the spinal cord, gives the benefit of increasing the exposure concentration even with a smaller number of cells [23], although there is a need for special surgical procedures to make the patients uncomfortable or other risks.

Multiple studies have been tried to discover the best administration route for improving therapeutic efficiency with a minimized dose amount in animal and human [24]. They have focused to expose the cells more to the target sites by changing carrier vehicles or administration route. Because the higher exposure of hAdMSCs to lesioned area with less cells in the brain compared to other treatment routes would compensate for inconvenience of IT administration. Many evidences suggested that IT injection does not induce noticeable adverse reaction in the animal disease models and human patients. The safety and feasibility of an IT injection of BMSCs were identified in multiple sclerosis patients [23]. The study also showed the efficacy can be seen at lower dose of hAdMSCs than with IV administration by changing of administration route into IT. An IT transplantation of bone-marrow-derived mononuclear cell was feasible and safe in a cerebral palsy patient for 2 years posttherapy assessment period, despite being a very young child [25]. Additional clinical case showed that multiple IT and IV administrations (total 7 times) did not induce any significant uncomfortableness except for a negligible fever during the treatment in 5-year-old girl suffering from cerebral palsy [26]. A retrospective study on cerebral palsy patients who received umbilical cord blood stem cells or BMMNCs treatment intrathecally in China and Lebanon $[27,28]$ supported that spinal cord injection might be safe and promising administration route. A large size of clinical study in 105 patients with cerebral palsy did not reveal any noticeable adverse effects by BMSCs transplantation into cerebrospinal cord during follow-up [29]. In case of spinal cord injury patients, several adverse events such as urinary tract infection, headache, nausea, and vomiting were observed during multiple IT treatments of autologous AdMSCs $\left(1 \times 10^{7}\right.$ cells $\left.\times 3\right)$ but resolved without special treatment [30]. Bonab et al. demonstrated that IT transplantation of BMSCs could give a favor in terms of dose level compared to IV injection in Multiple Sclerosis patients [23]. Combined IV and IT injections of BMSCs were well tolerated and safe in epilepsy patients [31]. IT treatment of the stem cells was safe in clinical trial for traumatic brain injured patients [32].

In healthy rabbits [33], there was no adverse response in general health, function and behavior including carcinogenetic evidence until 12 weeks after multiple IT administrations of autologous hAdMSCs (1 $\times 10^{7}$ cells $\times 3$ ). The transplanted amyotrophic lateral sclerosis mice did 
Citation: Jeong-Chan Ra, Hyo Jung Choi, Yoon Kim (2018) Safety of Multiple Intrathecal Administrations of Cultured Human Autologous AdiposeDerived Stem Cells in the Patients with Neurological Disorders Including Parkinson's Disease. J Clin Case Rep 8: 1183. doi: 10.4172/21657920.10001183

Page 5 of 6

not show any abnormal symptoms or pathologic changes related to the IT treatments of human embryonic stem cells in the blood, brain, and spinal cord [34].

We previously disclosed that the IV injection of hAdMSCs is permeable to blood brain barrier in mice models of AD and PD [15,35]. With expectation that IT administration can improve therapeutic efficiency by increasing exposure level in the brain, we have followed up on the patients who received IT treatment of the stem cells. To evaluate the safety and feasibility of multiple IT injections of hAdMSCs in the patients of neurologic disorder, we observed adverse reactions during and after repeated treatments of the cells in China and Japan from 2009 to 2017.

We already confirmed that the IV injection of hAdMSCs $\left(4 \times 10^{8}\right.$ cells) to the patients suffering from a spinal cord injury did not induce any serious adverse reaction related to the stem cells in our previous clinical study [36]. The retrospective study also supported the safety of repeated IV injections of hAdMSCs $\left(1 \times 10^{8}\right.$ cells/dose, total 2.743 $\sim 2.525$ billion cells) in the clinic [19].

The IT administration dose $\left(5 \times 10^{7} /\right.$ dose $)$ in the present study is lower compared with the IV administration doses $\left(4 \times 10^{8}\right.$ cells or $1 \times$ $10^{8} \mathrm{cells} /$ dose) used in our previous other clinical studies. Since the stem cells are expected to highly and directly be delivered to lesion site in the CNS by IT treatment $[20,37]$, the effective dose will be determined at lower dose without any adverse reactions than the IV dose in the clinic.

Number of IT administrations of hAdMSCs to the patients was varied from 1 to 25 in this study. It is difficult to prove which amount and times of doses are the best option now. However, we identified that multiple IT treatments might be safe and feasible, based on the results that nobody appealed serious adverse symptoms and uncomfortableness during IT treatment.

Some mild adverse reactions such as back pain, headache, dizziness, and fever were observed during treatment period. The symptoms appeared immediately or within 1 day after IT treatment but disappeared spontaneously without specific treatment. Back pain may most likely result from penetration of the needle into the spine. Short-term adverse symptoms such as headache, dizziness, and fever were observed in other clinical trials for the stem cells commonly, but they were not serious enough to stop the studies $[28,38]$ as in this study. Our study additionally supports safety of IT treatment of the stem cells by showing a suitable blood evaluation profile in the patients who received hAdMSCs. There was no statistical difference in blood chemistry analysis between before and after IT treatment. Three patients in the abnormal range were added than before the IT treatments of the cells. Because the patients are older, and the change is insignificant, it cannot be judged as an adverse reaction. These results indicate that multiple IT treatments of hAdMSCs might be safe in the clinic. There is a defect that the blood analysis results are not compared for all the patients who received IT treatment of the cells. Additional blood chemistry evaluation is required for the more robust evidence in the follow-up study.

Sixty-four patients were over 60-years-old. Fifty-four patients at early and late stage suffered from PD were involved in this study. Healthy condition should be maintained during the treatment period because long-term treatment is required to show therapeutic effects in the neurodegenerative diseases (ND). Considering most of ND patients are elderly people, the evidence that there are no adverse events in the PD patients would give a better opportunity for IT route for the administration.
We have continuously monitored adverse reactions from one year to over eight years after the last dose of the cells. However, none of the patients reported any unusual side effects or abnormal symptoms related to the cell treatment. IT treatment is expected in the CNS diseases that the less cells may be effective as blood brain barrier penetration is increased compared to IV and oral treatments. Moreover, IT route will save the cost and time required for treating the diseases because the therapeutic effect may be seen earlier than other treatment routes.

\section{Conclusion}

The IT treatment-induced inconvenience in our clinical study as well as in other studies was not serious or severe as predicted. Our study has a little limitation that ages and number of treatments in patients who received the cells were in wide range. However, it should be good and helpful evidence that there were no adverse reactions and inconveniences directly related to multiple IT injections of the cells to spine for long-term period.

In conclusion, this study strongly suggests that multiple IT administrations of the autologous adipose stem cells are safe for clinical use.

\section{References}

1. Hughes AJ, Daniel SE, Lees AJ (2001) Improved accuracy of clinical diagnosis of Lewy body Parkinson's disease. Neurol 57: 1497-1499.

2. Olanow CW, Tatton WG (1999) Etiology and pathogenesis of Parkinson's disease. Annu Rev Neurosci 22: 123-144.

3. Jellinger KA (2001) The pathology of Parkinson's disease. Adv Neurol 86: 55-72.

4. Müller T (2012) Drug therapy in patients with Parkinson's disease. Trans Neurodegeneration 1: 10-22.

5. Schapira AH, Bezard E, Brotchie J, Calon F, Collingridge GL, et al. (2006) Novel pharmacological targets for the treatment of Parkinson's disease. Nat Rev Drug Discov 5: 845-854.

6. Olanow CW, Schapira AH (2013) Therapeutic prospects for Parkinson disease. Ann Neurol 74: 337-347.

7. Blurton-Jones M, Kitazawa M, Martinez-Coria H, Castello NA, Muller FJ, et al. (2009) Neural stem cells improve cognition via BDNF in a transgenic model of Alzheimer disease. Proc Natl Acad Sci U S A 106: 13594-13599.

8. Glavaski-Joksimovic A, Bohn MC (2013) Mesenchymal stem cells and neuro regeneration in Parkinson's disease. Exp Neurol 247: 25-38.

9. Chang KA, Kim HJ, Joo Y, Ha S, Suh YH (2014) The therapeutic effects of human adipose-derived stem cells in Alzheimer's disease mouse models. Neurodegener Dis 13: 99-102.

10. Kim SU, Lee HJ, Kim YB (2013) Neural stem cell-based treatment for neurodegenerative diseases. Neuropathol 33: 491-504.

11. Duncan T, Valenzuela M (2017) Alzheimer's disease, dementia, and stem cell therapy. Stem Cell Research and Therapy 8: 111.

12. Moon J, Lee HS, Kang JM, Park J, Leung A, et al. (2013) Stem cell grafting improves both motor and cognitive impairments in a genetic model of Parkinson's disease, the aphakia (ak) mouse. Cell Transplant 22: 1263-1279.

13. Ziavra D, Makri G, Giompres P, Taraviras S, Thomaidou D, et al. (2012) Neural stem cells transplanted in a mouse model of Parkinson's disease differentiate to neuronal phenotypes and reduce rotational deficit. CNS Neurol Disord Drug Targets 11: 829-835.

14. Suzuki S, Kawamata J, Iwahara N, Matsumura A, Hisahara S, et al. (2015) Intravenous mesenchymal stem cell administration exhibits therapeutic effects against 6-hydroxydopamine-induced dopaminergic neurodegeneration and glial activation in rats. Neurosci Lett 584: 276-281.

15. Choi HS, Kim HJ, Oh JH, Park HG, Ra JC, et al. (2015) Therapeutic potentials of human adipose-derived stem cells on the mouse model of Parkinson's disease. Neurobiol Aging 36: 2885-2892.

16. Chi K, Fu RH, Huang YC, Chen SY, Hsu CJ, et al. (2018) Adipose-derived 
Citation: Jeong-Chan Ra, Hyo Jung Choi, Yoon Kim (2018) Safety of Multiple Intrathecal Administrations of Cultured Human Autologous AdiposeDerived Stem Cells in the Patients with Neurological Disorders Including Parkinson's Disease. J Clin Case Rep 8: 1183. doi: 10.4172/21657920.10001183

Page 6 of 6

stem cells stimulated with n-Butylidenephthalide exhibit therapeutic effects in a mouse model of Parkinson's Disease. Cell Transplant 27: 456-470.

17. Prockop DJ, Olson SD (2007) Clinical trials with adult stem/progenitor cells for tissue repair: Let's not overlook some essential precautions. Blood 109 3147-3151.

18. Herberts CA, Kwa MS, Hermsen HP (2011) Risk factors in the development of stem cell therapy. J Transl Med 9: 29.

19. Ra JC, Kim YJ, Kim EY (2017) Effect of the multiple intravenous administration of cultured human autologous adipose-derived stem cells on tumor biomarker levels. J Clinic Case Rep 7: 11.

20. Penn RD (2003) Intrathecal medication delivery. Neurosurg Clin N Am 14 381-387.

21. Volkman R, Offen D (2017) Concise review: Mesenchymal stem cells in neurodegenerative diseases. Stem Cells 35: 1867-1880.

22. Vidula N, Villa M, Helenowski IB, Merchant M, Jovanovic BD, et al. (2015) Adverse events during hematopoietic stem cell infusion: Analysis of the infusion product. Clin Lymphoma Myeloma Leuk 15: 157-162.

23. Bonab MM, Sahraian MA, Aghsaie A, Karvigh SA, Hosseinian SM, et al. (2012) Autologous mesenchymal stem cell therapy in progressive multiple sclerosis: An open label study. Curr. Stem Cell Res Ther 7: 407-414.

24. Anusha S, Basavarajk N, Vineeth C (2017) Stem cells: Cultivation and routes of administration. Curr Trends Biomedical Eng Biosci 2: 555579

25. Purandare C, Shitole DG, Belle V, Kedari A, Bora N, et al. (2012) Therapeutic potential of autologous stem cell transplantation for cerebral palsy. Case Rep Transplant 2012: 825-289.

26. Wang L, Ji H, Zhou J, Xie J, Zhong Z, et al. (2013) Therapeutic potential of umbilical cord mesenchymal stromal cells transplantation for cerebral palsy: A case report. Case Rep Transplant p: 146347

27. Abi Chahine NH, Wehbe TW, Hilal RA, Zoghbi VV, Melki AE, et al. (2016) Treatment of cerebral palsy with stem cells: A report of 17 cases. Int J Stem Cells 9: 90-95

28. Feng M, Lu A, Gao H, Qian C, Zhang J, et al. (2015) Safety of allogeneic umbilical cord blood stem cells therapy in patients with severe cerebral palsy: A retrospective study. Stem Cells Int p: 325652.

29. Liu X, Fu X, Dai G, Wang X, Zhang Z, et al. (2017) Comparative analysis of curative effect of bone marrow mesenchymal stem cell and bone marrow mononuclear cell transplantation for spastic cerebral palsy. J Transl Med 15: 48.

30. Hur JW, Cho TH, Park DH, Lee JB, Park JY, et al. (2016) IT transplantation of autologous adipose-derived mesenchymal stem cells for treating spinal cord injury: A human trial. J Spinal Cord Med 39: 655-664.

31. Hlebokazov F, Dakukina T, Ihnatsenko S, Kosmacheva S, Potapnev M, et al. (2017) Treatment of refractory epilepsy patients with autologous mesenchyma stem cells reduces seizure frequency: An open label study. Adv Med Sci 62 273-279

32. Wang Z, Luo Y, Chen L, Liang W (2017) Safety of neural stem cell transplantation in patients with severe traumatic brain injury. Exp Ther Med 13: 3613-3618.

33. Izrael M, Slutsky SG, Admoni T, Cohen L, Granit A, et al. (2018) Safety and efficacy of human embryonic stem cell-derived astrocytes following IT transplantation in SOD1G93A and NSG animal models. Stem Cell Res Ther 9: 152.

34. Chen BK, Staff NP, Knight AM, Nesbitt JJ, Butler GW, et al. (2015) A safety study on IT delivery of autologous mesenchymal stromal cells in rabbits directly supporting Phase I human trials. Transfusion 55: 1013-1020.

35. Chang KA, Lee JH, Suh YH (2014) Therapeutic potential of human adiposederived stem cells in neurological disorders. J Pharmacol Sci 126: 293-301.

36. Ra JC, Shin IS, Kim SH, Kang SK, Kang BC, et al. (2011) Safety of intravenous infusion of human adipose tissue-derived mesenchymal stem cells in animals and humans. Stem Cells Dev 20: 1297-1308.

37. Thorne RG, Frey WH (2001) Delivery of neurotrophic factors to the central nervous system: Pharmacokinetic considerations. Clin Pharmacokinet 40: 907 946.

38. Karussis D, Karageorgiou C, Vaknin-Dembinsky A, Gowda-Kurkalli B, Gomor JM, et al. (2010) Safety and immunological effects of mesenchymal stem cell transplantation in patients with multiple sclerosis and amyotrophic lateral sclerosis. Arch Neurol 67: 1187-1194. 